\title{
The First Case of Covid-19 in South Kalimantan
}

\author{
Muhammad Nor*, Haryati \\ Department of Pulmonology and Respiratory Medicine, Faculty of Medicine, Lambung Mangkurat University/Ulin General \\ Hospital, Banjarmasin, Indonesia.
}

\section{ARTICLE INFO}

Article history:

Received 17 August 2020

Received in revised form 25

September 2020

Accepted 28 September 2020

Available online 30 September 2020

\section{Keywords:}

Covid-19,

SARS-CoV-2,

First case,

Severe case,

South Kalimantan

\begin{abstract}
Background: In December 2019, a series of acute respiratory syndromes occurred in Wuhan, China. This syndrome became known as severe acute respiratory syndrome coronavirus 2 (SARS-CoV-2). The sudden appearance and rapid global spread of SARS-CoV-2 led World Health Organization (WHO) to declare it as a pandemic disease on March 11, 2020. We will report the first case COVID-19 in South Kalimantan.

Case: A 44 years old man was presented with fever, 7 days before admission. The patient also complained about cough with white phlegm and shortness of breath, accompanied by nausea with heartburn and decreased of appetite. He confessed that he just returned from local transmission areas of COVID-19. From physical examination, it was found $\mathrm{SaO} 292 \%$ room air with bronchial sounds and ronchi in the lung. Chest Xray showed peripheral infiltrates and diagnostic swab with RT-PCR in the oropharynx and nasopharynx showed that the patient was infected with SARS-CoV-2. HbsAg marker on this patient was also reactive. The patient then received supportive therapy as well as antiviral therapy. After 10 days of treatment, the patient was already free from the symptom, but swab evaluation remained positive. On the 31 st day of treatment, the patient was finally declared cured with a negative swab result.

Conclusion: The number of COVID-19 cases has increased from time to time. Holistic treatment and rapid detection greatly affect the prognosis of this disease. Prevention through health protocols is also very important to reduce its spread.
\end{abstract}

\section{BACKGROUND}

In December 2019, a series of acute respiratory syndromes occurred in Wuhan, China. This syndrome quickly spread from Wuhan to other places. The cause of this incident turned out to be a novel coronavirus. This syndrome became known as severe acute respiratory syndrome coronavirus 2 (SARS-CoV-2). ${ }^{1}$

The sudden emergence and rapid global spread of SARS-CoV-2 led World Health Organization (WHO) to declare it as a pandemic disease on March 11, 2020. The Chinese Center for Disease Control and Prevention reported 44,500 confirmed cases in China, where about $80 \%$ had mild symptoms, $14 \%$ had severe symptoms, and $5 \%$ had critical symptoms. ${ }^{2,3}$

Coronavirus is an RNA virus with a particle size of 120-160 nm. This virus can spread through humans and other mammals. Before the outbreak, there were 6 types of coronavirus that could infect humans. The disease that arises from SARS-CoV-2 is called Coronavirus Diseases 19 (COVID-19)., 4

The clinical symptoms of COVID-19 patients are extensive. Starting from no symptoms, mild symptoms, pneumonia, severe pneumonia, ARDS, sepsis, and septic shock. The most common symptoms, based on data from 55,924 cases, were fever, dry cough, and fatigue. Meanwhile, other symptoms that can be found are productive cough, shortness of breath, coughing up blood, sore throat, headache, myalgia, atralgia, chills, nausea, vomiting, and diarrhea. ${ }^{6,7}$

The risk factors for developing this disease include smoking, diabetes, hypertension, and male. This is due to the increased expression of angiotensinconverting enzyme 2 (ACE2) receptors. Then patients with cancer and chronic liver disease were also risk factors for developing this disease..$^{8-10}$

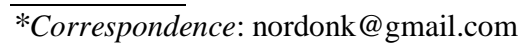


Examinations that can be done to diagnose SARS-CoV-2 cases are swabs (in the oropharynx and nasopharynx) with the reverse-transcriptase polymerase chain reaction (RT-PCR) method, complete blood count, blood chemistry, blood clotting factors, and radiology. On complete blood count, we usually found leucopenia, lymphocytopenia, increased hepatic enzymes, increased CRP, increased D-Dimer, and increased ferritin. Meanwhile, radiological examinations are chest X-ray and CT-Scan that usually reveal bilateral ground-glass opacities (GGO). The lesions are usually found in peripheral areas. ${ }^{11}$

In Indonesia, there have been 43,803 confirmed cases (till June 19, 2020), where the first case was found on March 2, 2020. In South Kalimantan, there have been 2,392 confirmed cases. In this case report, we will discuss the first case in South Kalimantan, which was diagnosed based on swabs that was performed on March 15 and 16, 2020.

\section{CASE}

A 44 years old man initially complained about fever, 7 days before being admitted to the hospital. Cough with white phlegm occurred since the last 4 days. Cough occurred especially when he took a deep breath. Shortness of breath occurred since the last 2 days. In addition, he also complained about nausea accompanied by heartburn since 3 days ago and decreased appetite since the last 4 days. The patient had history of travelling to Singapore 2 weeks ago and then went to Malang, Madura, and Bali 8 days ago. Those places are classified as local transmission area of COVID-19.

From the physical examination when the patient came in to the hospital, we found tachycardia, bronchial sounds, and ronkhi on both of hemithorax with saturation of $92 \%$ on room air.

From chest X-ray examination (Figure 1), there were infiltrates on both side of hemithorax, especially on the peripheral of lungs.
The first laboratory examinations showed increased neutrophils $(83.1 \%)$ and decreased lymphocytes (11.3\%) with ALC 850 and NLR 7.71. There was also increased liver enzymes (AST 104 and ALT 123) and decreased renal functions (ureum 52 and creatinine 1.7). Because the patient was suspected with COVID-19, we also did the swab diagnostic on March 15 and 16, 2020 in which the result was positive.

The patient was treated from March 14, 2020 to April 13, 2020 (31 days of treatments). After 10 days of treatments, the patient did not have any more complaint, but he was still in isolation ward due to positive swab evaluations. Nevertheless, after 3rd evaluations (on $28^{\text {th }}$ and $29^{\text {th }}$ day of treatment), the swab result became negative and he was discharged.

During admission, the patient did some examinations. From the laboratory perspective, we did serial of complete blood counts, blood chemistry, the inflammation marker (CRP and LDH), blood and sputum cultures, and hepatitis marker. We found that his ALC and NLR were getting better and his inflammation markers were decreased. Same things happened to his renal and liver functions, it got better on every examination. Although on the last day, we found his liver enzymes increased. His HbsAg marker result was also positive. From his culture specimens (blood and sputum), we did not find any bacterial colonization.

The patient did several chest X-ray to evaluate the condition of the lunga. As we can see in Figure 2, his condition was getting better everyday.

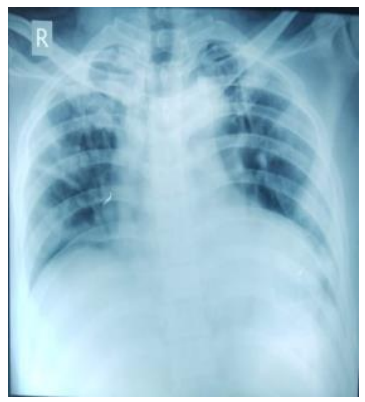

Figure 1. Chest X-ray oon March 16, 2020 there were infiltrates on both side of hemithorax.
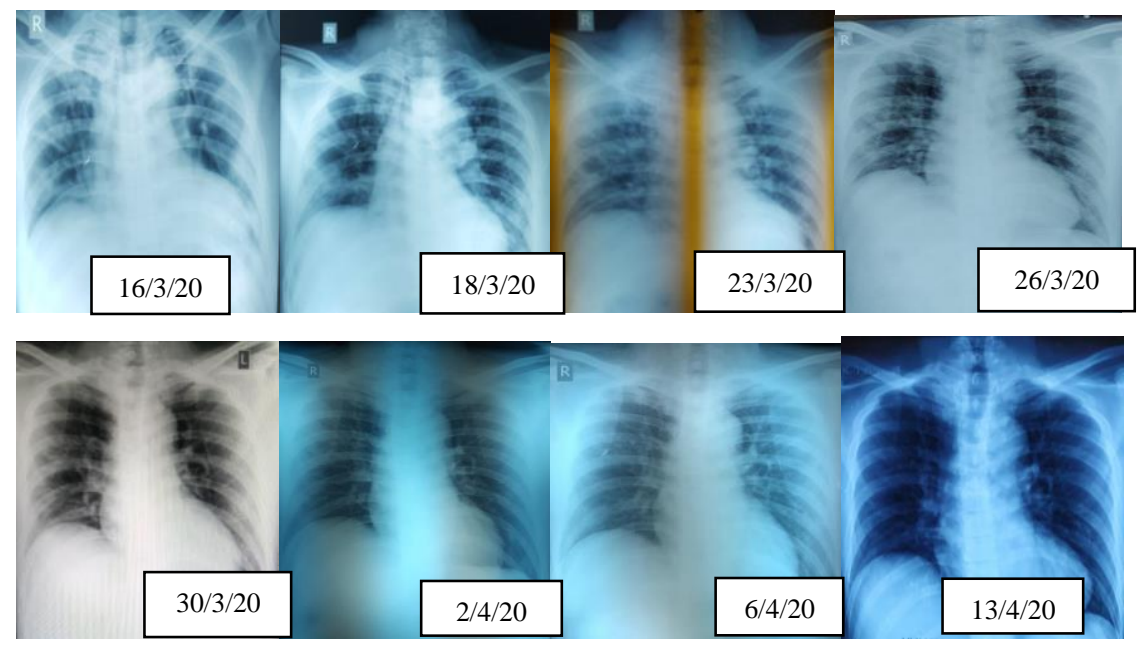

Figure 2. Gradual improvement of the chest $\mathrm{X}$-ray images as the infiltrates diminished 
Table 1. Laboratory Results

\begin{tabular}{|c|c|c|c|c|c|c|c|c|c|c|c|c|}
\hline \multirow{2}{*}{ Parameter } & \multirow{2}{*}{$\begin{array}{c}\text { Normal } \\
\text { Value }\end{array}$} & \multicolumn{11}{|c|}{ Day of Treatment (DT) and Day of Onset (DO) } \\
\hline & & $\begin{array}{l}\text { DT-2 } \\
\text { DO-9 }\end{array}$ & $\begin{array}{c}\text { DT-4 } \\
\text { DO-11 }\end{array}$ & $\begin{array}{c}\text { DT-5 } \\
\text { DO-12 }\end{array}$ & $\begin{array}{c}\text { DT-8 } \\
\text { DO-15 }\end{array}$ & $\begin{array}{l}\text { DT-10 } \\
\text { DO-17 }\end{array}$ & $\begin{array}{l}\text { DT-13 } \\
\text { DO-20 }\end{array}$ & $\begin{array}{l}\text { DT-17 } \\
\text { DO-24 }\end{array}$ & $\begin{array}{l}\text { DT-20 } \\
\text { DO-27 }\end{array}$ & $\begin{array}{l}\text { DT-24 } \\
\text { DO-31 }\end{array}$ & $\begin{array}{l}\text { DT-27 } \\
\text { DO-34 }\end{array}$ & $\begin{array}{l}\text { DT-31 } \\
\text { DO-38 }\end{array}$ \\
\hline $\mathrm{Hb}$ & $12-16$ & 16.6 & 16.1 & 16.4 & 14.1 & 13.7 & 13.4 & 14.7 & 15.5 & 14.4 & 15.2 & 14.9 \\
\hline Leucosit & 4-10.5 & 7.8 & 5.5 & 4.1 & 4.7 & 4.6 & 3.5 & 5.2 & 6 & 6.7 & 6.9 & 6.7 \\
\hline Erythrocyte & 4-5.30 & 5.6 & 5.44 & 5.46 & 4.79 & 4.71 & 4.59 & 5 & 4.81 & 4.81 & 5.06 & 4.95 \\
\hline Hematocrit & $37-47$ & 49.9 & 49 & 49.6 & 42 & 41.6 & 41.2 & 46 & 48 & 43.3 & 45.8 & 45.5 \\
\hline Platelet & $150-450$ & 272 & 234 & 241 & 255 & 333 & 355 & 347 & 279 & 189 & 210 & 224 \\
\hline MCV & $75-96$ & 88 & 90.1 & 90.8 & 87.7 & 88.3 & 89.8 & 92 & 90.7 & 90.0 & 90.5 & 91.9 \\
\hline MCH & 28-32 & 29 & 29.6 & 30 & 29.4 & 29.1 & 29.2 & 29.4 & 29.3 & 29.9 & 30.0 & 30.1 \\
\hline MCHC & 33-37 & 33.3 & 32.9 & 33.1 & 33.6 & 32.9 & 32.5 & 32 & 32.3 & 33.3 & 33.2 & 32.7 \\
\hline $\begin{array}{l}\text { Eosinophil } \\
\% / \#\end{array}$ & $1-3 /<3$ & $2.2 / 0.1$ & $0.9 / 0.5$ & $1.7 / 0.07$ & $1.9 / 0.09$ & $3.1 / 0.14$ & $5.8 / 0.2$ & $4.4 / 0.23$ & $5.9 / 0.35$ & $5.7 / 0.38$ & $5.0 / 0.35$ & $5.8 / 0.39$ \\
\hline Basophil \%/\# & $0-1 /<1$ & $0.1 / 0.3$ & - & $0.5 / 0.02$ & $0.2 / 0.01$ & $0.4 / 0.02$ & $0.3 / 0.01$ & $0.8 / 0.04$ & $0.3 / 0.02$ & $0.1 / 0.01$ & $0.3 / 0.02$ & $0.1 / 0.01$ \\
\hline Neutrophyl \%/\# & $50-81 / 2.5-7$ & $83.1 / 6.79$ & $76.5 / 4.23$ & $70.7 / 2.9$ & $72.0 / 3.40$ & $57.6 / 0.91$ & $48.1 / 1.66$ & $61.8 / 3.19$ & $65.1 / 3.87$ & $68.2 / 4.56$ & $60.4 / 4.19$ & $58.1 / 3.87$ \\
\hline Limphocyt \%/\# & $20-40 / 1.25-4$ & $11.3 / 1.63$ & $15 / 0.83$ & $19.8 / 0.81$ & $14.2 / 0.67$ & $20 / 0.91$ & $24.9 / 0.86$ & $19.5 / 1.01$ & $19.5 / 1.16$ & $15.7 / 1.05$ & $22.8 / 1.58$ & $25.2 / 1.68$ \\
\hline Monocyte\%/\# & 2-8/0.3-1 & $5.5 / 0.59$ & - & $7.3 / 0.3$ & - & $18.9 / 0.86$ & $20.9 / 0.72$ & $13.5 / 0.7$ & $9.2 / 0.55$ & $10.3 / 0.69$ & $11.5 / 0.80$ & $10.8 / 0.72$ \\
\hline NLR & $<3.13$ & 7.35 & 5.1 & 3.57 & 5.07 & 2.88 & 1.93 & 3.17 & 3.33 & 4.34 & 2.65 & 2.30 \\
\hline ALC & $>1500$ & 881.4 & 825 & 811.8 & 667 & 920 & 871.5 & 1010 & 1170 & 1050 & 1570 & 1688 \\
\hline Glucose & $<200$ & 106 & - & - & 116 & - & - & - & - & 109 & 71 & 64 \\
\hline SGOT & $5-34$ & 104 & 152 & 87 & 42 & 33 & - & 36 & - & 49 & 77 & 81 \\
\hline SGPT & $0-55$ & 123 & 184 & 120 & 86 & 49 & - & 42 & - & 59 & 96 & 118 \\
\hline Albumin & 3.5-4.2 & - & - & 3,4 & - & - & - & - & - & - & - & - \\
\hline Total Bil. & $0.2-1.2$ & - & - & 1.59 & 1.5 & 0.92 & - & - & - & 0.54 & - & 0.81 \\
\hline Direct Bil. & $0-0.2$ & - & - & 0.72 & 0.67 & 0.33 & - & - & - & 0.22 & - & 0.3 \\
\hline Indirect Bil. & $0.2-0.8$ & - & - & 0.87 & 0.83 & 0.59 & - & - & - & 0.32 & - & 0.51 \\
\hline Ureum & 0-50 & 52 & 59 & 47 & 21 & - & - & 24 & 21 & 24 & 21 & 19 \\
\hline Creatinin & 0.57-1.11 & 1.7 & 1.42 & 1.2 & 1.1 & - & - & 1.3 & 1.4 & 1.22 & 1.28 & 1.14 \\
\hline Sodium & 136-145 & - & 136 & - & 137 & - & - & - & - & - & 138 & 142 \\
\hline Potassium & $3.5-5.1$ & - & 4.1 & - & 4.2 & - & - & - & - & - & 4 & 3.9 \\
\hline Chlorida & 98-107 & - & 100 & - & 108 & - & - & - & - & - & 106 & 109 \\
\hline LDH & $125-220$ & - & - & 408 & - & - & - & - & - & - & - & 230 \\
\hline CRP & $<6$ & 48 & 48 & - & - & - & - & - & - & 6 & $<6$ & $<6$ \\
\hline HbsAg & $<1$ & - & - & $\begin{array}{c}5922 \\
\text { (reactive) }\end{array}$ & - & - & - & - & - & - & - & - \\
\hline
\end{tabular}


When the patient was being treated, he was given mostly supportive treatments. We gave fluid therapy with normal saline $20 \mathrm{dpm}$, oxygen therapy with nasal canulle 3-4 lpm, vitamins (vitamin $\mathrm{C}$ and vitamin D), probiotics, and mineral. We also gave him hepatoprotector because of increased liver enzymes. Since we could not rule out the possibility of bacterial pneumonia, he also got antibiotics. On the first day, the patient got meropenem 1 gr every 8 hours and moxifloxacin $400 \mathrm{mg}$ once a day. Nevertheless, after 3 days of treatment, we decided to also give vancomycin 1 gr every 12 hours because of the risk of MRSA infection. These antibiotics were given until 10 days of treatments. After the result of swab came out, we gave him hydroxychloroquine with loading dose $400 \mathrm{mg}$, and continue with $200 \mathrm{mg}$ every 12 hour. The patient also received azithromycin $500 \mathrm{mg}$ once a day. Lastly, we gave the patient antivirals. The first one was oseltamivir $75 \mathrm{mg}$, twice a day, and the second one was a combination of lopinavir $200 \mathrm{mg}$ and ritonavir $50 \mathrm{mg}$, twice a day. Supportive therapy was also included. The patient got proper nutrition based on his condition.

\section{DISCUSSION}

COVID-19 has various clinical symptoms which are grouped into mild, moderate, severe, and critical symptoms. ${ }^{5,12,13}$ In our case, the patient started complaining about fever up to 7 th day of disease onset. This is according to the theory which stated that the incubation period of the disease ranges from 3-14 days (with a median of 5 days). Then on the 4th day of disease's onset, the patient began to complain of coughing. Accompanied by complaints of nausea on day 5. At its peak, the patient complained shortness of breath from day 10 of onset. All of these complaints occur when SARS-CoV-2 virus attacks epithelial of alveolar cells, especially type 2 epithelial cells that secretes ACE2 receptors. This virus will activate the innate immune system and macrophages which aim not only to phagocyte viruses but also to release cytokines and chemokines. This adaptive immune system was also induced by antigen presenting cells (APC). This will cause the secretion of pro-inflammatory cytokines and cause fever. In addition, intra-alveolar exudates and erythrocytes will form, which stimulate coughing and cause shortness of breath. The patient also complained of nausea, in which there are 2 theories that can explain it. First, the presence of ACE2 receptors in the digestive tract tissue that triggers inflammation, especially in the small intestine. This can also trigger diarrhea in COVID19 patients. The second theory states that there was disruption in dorsal vagal complex (DVC) located in the medulla oblongata. The ACE2 receptors on DVC can be attacked via epithelium of the nasopharynx. In addition, it can spread through the blood through the blood-brain barrier (BBB). ${ }^{3,14-16}$

In this case, we performed many examinations. Starting from the chest photo examination. The first chest X-ray was taken at the onset of the disease on day 5 , the photo showed an infiltrate in both of hemithorax, accompanied by a thickening of the hilus. Then it was repeated again at day 10 of the onset or 3rd day of treatment. It showed that the infiltrates increased. This occurred because of the formation from intra-alveolar exudates and erythrocytes due to the inflammatory process of COVID-19. After the patient was treated, there was a gradual improvement of the chest X-ray images as the infiltrate diminished. ${ }^{14}$

The laboratory examination showed an increase in neutrophils and a decrease in lymphocytes with a neutrophil-lymphocyte ratio (NLR) value increased. An increase in NLR value (> 3.13) can be used as a sign of viral infection. This is due to viral infection causes a decrease in $\mathrm{CD}^{+}$T-lymphocytes and an increase in $\mathrm{CD}^{+} \mathrm{T}$-lymphocyte suppressors. However, this sign was not specific to SARS-CoV-2 infection. Conversely, this NLR value can be used as a prediction about patient's deterioration, especially in patients aged over 50 years old. The study was stated that in patients aged over 50 years old with an NLR value $>3.13$, there is a $50 \%$ chance of worsening to a more severe condition. ${ }^{17}$ 
Table 3. Progress of symptoms

\begin{tabular}{|c|c|c|c|c|c|c|c|c|c|c|c|c|c|c|c|c|c|c|}
\hline Day of onset & 1 & 2 & 3 & 4 & 5 & 6 & 7 & 8 & 9 & 10 & 11 & 12 & 13 & 14 & 15 & 16 & 17 & $18-38$ \\
\hline $\begin{array}{l}\text { Day of } \\
\text { treatment }\end{array}$ & - & - & - & - & - & - & - & 1 & 2 & 3 & 4 & 5 & 6 & 7 & 8 & 9 & 10 & $11-31$ \\
\hline Fever & & & & & & & & & & & & & & & & & & \multirow{5}{*}{ No symptoms } \\
\hline Cough & & & & & & & & & & & & & & & & & & \\
\hline $\begin{array}{l}\text { Shortness of } \\
\text { breath }\end{array}$ & & & & & & & & & & & & & & & & & & \\
\hline Nausea & & & & & & & & & & & & & & & & & & \\
\hline Diarrhea & & & & & & & & & & & & & & & & & & \\
\hline
\end{tabular}

Other laboratory tests which were abnormal were an increase in AST and ALT values. In patients with COVID-19, this is usually caused by three things, (1) the drugs which are used for treatment, (2) systemic inflammatory response syndrome, and (3) hypoxiareperfusion dysfunction. Many drugs which are used in patients with COVID-19 can cause liver dysfunction, such as some antipyretics and antivirals. In our case, the patient received antipyretic therapy (paracetamol) while being treated at previous hospital. This may be the factor that worsened liver function when the patient was referred to our hospital. The systemic inflammatory response syndrome that occurs in patients with COVID19 can cause impaired liver function due to activation of $\mathrm{T}$ cells, which produces granulocyte-macrophage colony-stimulating factor (GM-CSF), interleukin (IL)-6, and other inflammatory factors. This will cause an inflammation storm and damage the organs, including the liver. This may also explain why there is impairment in kidney function. Finally, the hypoxia-reperfusion dysfunction process can cause liver dysfunction due to lack of oxygen and accumulation of lipids in hepatocytes during shock and hypoxic conditions, resulting in cell death. It will increase reactive oxygen and produces peridoxidation products that activate the redox-sensitive transcription factor which increases proinflammatory factors and causes damage to the liver. Because the patient was suffering from hepatitis $\mathrm{B}$, it was rather difficult to determine the cause of the impaired liver function, whether because the hepatitis flared due to infection from the SARS-CoV-2 or due to direct infection from SARS-CoV-2. However, based on a study that was conducted in China, chronic hepatitis B does not affect the recovery from COVID-19. Although, hepatitis $\mathrm{B}$ patients with hepatic cirrhosis have a higher risk of contracting COVID-19 due to immune dysfunction. Another marker that was increased was Creactive protein (CRP). Increased CRP correlated with the degree of inflammation. An increase in CRP at the early onset maybe correlated with pneumonia. In addition, CRP value is usually directly proportional to the number of infiltrate lesions in the lungs. ${ }^{18-20}$

The diagnosis of this case was performed with nasopharyngeal and oropharyngeal swabs using RTPCR method. Diagnostic swabs were performed on the $2^{\text {nd }}$ and $3^{\text {rd }}$ day of treatment. Then the patient did the first swab evaluation on the $14^{\text {th }}$ and $15^{\text {th }}$ day of treatment and the second one was on the $24^{\text {th }}$ and $25^{\text {th }}$ day of treatment, but the results were still positive. He was declared cured after the third swab evaluation on the $28^{\text {th }}$ and $29^{\text {th }}$ day of treatment. The patient was actually asymptomatic since day 11 of treatment (day 18 of onset). Several studies stated that average patient had a negative swab evaluation between 9 to 16 days after onset. However, there are some cases with persistent positives. This can be caused by 5 things. First, because of the coexistence between SARS-CoV-2 and the immune system. This is resulted in the absence of a further pro inflammatory condition. Second, low antibody production. It can also lead to a condition in which the patient may be asymptomatic but is still not completely clear from the virus. Third, the ability of SAR-CoV-2 to evade the immune system after it had previously been detected and resisted. This virus will hide in tissues or glands that can tolerate the presence of foreign objects without triggering an inflammatory reaction, for example in the salivary glands. Fourth, there was reactivation or reinfection of SARS-CoV-2. Many researchers stated in SARS-CoV-2 cases that it was most likely from reactivation, but it did not rule out the possibility of new reinfection from outside if there was a disturbance in the immune system. Fifth, 
intermittent viral shedding. This theory explains that the virus sheds periodically, causing continuous positive swab results. The viral shedding of SARS-CoV-2 ranged from 8 to 37 days after symptom onset, with a mean of 20 days. Nevertheless, the longest record was 60 days after onset. $^{21-25}$

Most treatments for COVID-19 cases was supportive. In our case, the therapy had been performed in accordance with existing procedures, such as patient isolation and control of infection transmission, oxygen supplementation and symptomatic therapy, serial chest $\mathrm{X}$-ray to assess disease progression, monitoring signs of respiratory failure, proper and adequate fluid administration, empiric antibiotic therapy for pneumonia, and comorbid monitoring. Antibiotics that were given to the patient was betalactam and fluoroquinolone, then the patient also received additional antibiotic (vancomycin) because of the risk of MRSA. The patient also received hepatoprotector to protect liver function and vitamins as well as probiotics and minerals. The vitamins received were vitamin $\mathrm{C}$ and vitamin D. Vitamin $\mathrm{C}$ is useful for the formation and maturation of $\mathrm{T}$ lymphocytes and NK cells, which will help increase the immune response to viral infections and then vitamin $\mathrm{D}$, apart from being a stimulant for the induction of $\mathrm{T}$ cells, also functions as respiratory homeostasis by stimulating exhibits of antimicrobacterial peptides or directly interfering with the replication of the virus. In addition, hydroxychloroquine (HCQ) and azithromycin were also given as specific therapies for COVID-19. The mechanism of HCQ, among others, is an inhibitor of viral enzymes, such as viral polymerase and viral protein glycosylation. This will cause interference with virus formation, the delivery of virus particles, and releasing from the virus. Another mechanism of HCQ is to inhibit viral adhesion to cell membranes and release cytokines. Meanwhile, the mechanism of azithromycin is to downregulate the inflammatory response and reduce the production of excessive cytokines through inhibition of chemotaxis from neutrophils to the lungs, reducing mucus hypersecretion, increasing neutrophil apoptosis, and blocking activation of nuclear transcription factors. Antivirals in this case used broad-spectrum antivirals such as nucleoside analogues. The patient was given oseltamivir. The way oseltamivir works based on in vitro studies shows no antivirus activity on SARS-CoV2. Although there is no strong evidence, we still gave oseltamivir because at that time only this drug was available and was still allowed by WHO. Nevertheless, 5 days before the patient was discharged, we also gave the combination of lopinavir and ritonavir. The way lopinavir/ritonavir works was by binding to the M-pro enzyme, which is an important enzyme for coronavirus replication. Although in some studies giving lopinavir/ritonavir did not provide any special benefits, a report from Korea stated that this drug significantly decreased the titer of coronavirus. Later on, we gave zinc and probiotics. Zinc plays a role in stabilizing the cell membrane which contributes to blocking the entry of viruses and inhibits viral replication by altering the proteolytic processes of the replication polyprotein and RNA-dependent RNA polymerase (RdRp). Finally, the provision of probiotics was based on the same reasons as zinc administration, because probiotics can block or inactivate RdRp so it will prevent virus replication. ${ }^{26-31}$

Since COVID-19 was a novel disease, there was not any patent guideline. When we treated our first patient, most of our drugs was based on newly released journals. Therefore, we tried to mix the best combination of drugs. We realized there was many weaknesses in our report, but we hope at least it will give some highlight.

\section{CONCLUSION}

A 44 years old man with severe COVID-19 and hepatitis B was the first COVID-19 case in South Kalimantan. After 10 days of treatment, the patient was free of complaints. However, the patient was treated for up to 30 days until the evaluation swab was two times negative. During treatment, the patient received oxygen therapy, vitamins, probiotics, mineral, empiric antibiotics, and specific therapy for COVID-19. The patient was discharged with a good condition where the patient was able to do activities without hindrance. Holistic treatments and rapid detection greatly affected the prognosis of this disease. Prevention through health protocols is also very important to reduce its spread. 


\section{REFERENCES}

1. Yuki K, Fujiogi M, Koutsogiannaki S. COVID-19 Pathophysiology: A Review. Clin Immunol 2020; 215: 108427.

2. Vabret N, Britton GJ, Gruber C, et al. Immunology of COVID-19: Current State of the Science. Immunity 2020; 52: 910-941.

3. Merad M, Martin JC. Pathological Inflammation in Patients with COVID-19: A Key Role for Monocytes and Macrophages. Nat Rev Immunol 2020; 20: 355-362.

4. Riedel S, Morse SA, Mietzner TA, et al. Jawetz, Melnick \& Adelberg's Medical Microbiology. 2019.

5. Rothan HA, Byrareddy SN. The Epidemiology and Pathogenesis of Coronavirus Disease (COVID-19) Outbreak. J Autoimmun 2020; 109: 102433.

6. Organization WH. Report of the WHO-China Joint Mission on Coronavirus Disease 2019 (COVID19). Geneva, https://www.who.int/docs/defaultsource/coronaviruse/who-china-joint-mission-oncovid-19-final-report.pdf (2020).

7. Kam K-Q, Yung CF, Cui L, et al. A Well Infant with Coronavirus Disease 2019 with High Viral Load. Clin Infect Dis an Off Publ Infect Dis Soc Am 2020; 71: 847-849.

8. Cai H. Sex Difference and Smoking Predisposition in Patients with COVID-19. The Lancet. Respiratory Medicine 2020; 8: e20.

9. Fang L, Karakiulakis G, Roth M. Are Patients with Hypertension and Diabetes Mellitus at Increased Risk for COVID-19 Infection? The Lancet. Respiratory Medicine 2020; 8: e21.

10. Zhang C, Shi L, Wang F-S. Liver Injury in COVID-19: Management and Challenges. Lancet Gastroenterol Hepatol 2020; 5: 428-430.

11. Sharma R, Agarwal M, Gupta M, et al. Clinical Characteristics and Differential Clinical Diagnosis of Novel Coronavirus Disease 2019 (COVID-19). Coronavirus Disease 2019 (COVID-19): Epidemiology, Pathogenesis, Diagnosis, and Therapeutics 2020; 55-70.

12. Gorbalenya AE, Baker SC, Baric RS, et al. The Species Severe Acute Respiratory SyndromeRelated Coronavirus: Classifying 2019-nCoV and Naming It SARS-CoV-2. Nat Microbiol 2020; 5: 536-544.

13. Zhou P, Yang X-L, Wang X-G, et al. A Pneumonia Outbreak Associated with a New Coronavirus of Probable Bat Origin. Nature 2020; 579: 270-273.

14. Susilo A, Rumende C, Pitoyo C, et al. Coronavirus Disease 2019: Tinjauan Literatur Terkini. J Penyakit Dalam Indones 2020; 7: 45.

15. Chigr F, Merzouki M, Najimi M. Autonomic Brain Centers and Pathophysiology of COVID-19. ACS Chem Neurosci 2020; 11: 1520-1522.
16. Ng SC, Tilg H. COVID-19 and the Gastrointestinal Tract: More than Meets the Eye. Gut 2020; 69: 973-974.

17. Liu J, Liu Y, Xiang $\mathrm{P}$, et al. Neutrophil-toLymphocyte Ratio Predicts Severe Illness Patients with 2019 Novel Coronavirus in the Early Stage. medRxiv 2020; 2020.02.10.20021584.

18. Feng G, Zheng KI, Yan Q-Q, et al. COVID-19 and Liver Dysfunction: Current Insights and Emergent Therapeutic Strategies. J Clin Transl Hepatol 2020; 8: 18-24.

19. Boettler T, Newsome PN, Mondelli MU, et al. Care of Patients with Liver Disease during the COVID-19 Pandemic: EASL-ESCMID Position Paper. JHEP Reports Innov Hepatol 2020; 2: 100113.

20. Wang L. C-Reactive Protein Levels in the Early Stage of COVID-19. Med Mal Infect 2020; 50: 332-334.

21. Zhang L, Li C, Zhou Y, et al. Persistent Viral Shedding Lasting Over 60 Days in a Mild COVID19 Patient with Ongoing Positive SARS-CoV-2. Quant Imaging Med Surg 2020; 10: 1141-1144.

22. Carmo A, Pereira-Vaz J, Mota V, et al. Clearance and Persistence of SARS-CoV-2 RNA in Patients with COVID-19. J Med Virol 2020; 92: 22272231.

23. Yang J-R, Deng D-T, Wu N, et al. Persistent viral RNA Positivity during the Recovery Period of a Patient with SARS-CoV-2 Infection. J Med Virol. Epub ahead of print April 2020. DOI: 10.1002/jmv.25940.

24. Ravioli S, Ochsner H, Lindner G. Reactivation of COVID-19 pneumonia: A Report of Two Cases. The Journal of Infection 2020; 81: e72-e73.

25. Wong J, Koh WC, Momin RN, et al. Probable Causes and Risk Factors for Positive SARS-CoV-2 Test in Recovered Patients: Evidence from Brunei Darussalam. J Med Virol. Epub ahead of print June 2020. DOI: 10.1002/jmv.26199.

26. Wu R, Wang L, Kuo H-CD, et al. An Update on Current Therapeutic Drugs Treating COVID-19. Curr Pharmacol Reports 2020; 1-15.

27. Ali N. Role of Vitamin D in Preventing of COVID19 Infection, Progression and Severity. J Infect Public Health. Epub ahead of print 2020. DOI: https://doi.org/10.1016/j.jiph.2020.06.021.

28. Burhan E, Isbaniah F, Susanto AD. Pneumonia COVID-19: Diagnosis \& Penatalaksanaan di Indonesia. Jakarta Perhimpun Dr Paru Indones.

29. Smith T, Bushek J, LeClaire A, et al. COVID-19 Drug Therapy. Elsevier.

30. Kumar A, Kubota Y, Chernov M, et al. Potential Role of Zinc Supplementation in Prophylaxis and Treatment of COVID-19. Med Hypotheses 2020; 144: 109848. 
31. Anwar F, Altayb HN, Al-Abbasi FA, et al. Antiviral Effects of Probiotic Metabolites on COVID-19. J Biomol Struct Dyn 2020; 1-10. 